\title{
A Study of Cardiovascular Function in Tsumura Suzuki Obese Diabetes, a New Model Mouse of Type 2 Diabetes
}

\author{
Tomie Kawada, ${ }^{*}, a$ Shigeo Miyata, ${ }^{a}$ Tsutomu Shimada, ${ }^{a}$ Yoshiki Sanzen,,${ }^{b}$ Minami Ito, ${ }^{b}$ \\ Chieko Hemmi, ${ }^{a}$ Seiichi Irzuka, ${ }^{a}$ Wataru Suzuki,${ }^{a}$ Kiyoshi Minara, ${ }^{a}$ \\ Masaki AbURAdA, ${ }^{a}$ and Mikio NAKAZAWA ${ }^{b}$ \\ ${ }^{a}$ Research Institute of Pharmaceutical Sciences, Musashino University; 1-1-20 Shinmachi, Nishitokyo, Tokyo 202-8585, \\ Japan: and ${ }^{b}$ Department of Medical Technology, School of Health Science, Faculty of Medicine, Niigata University; 2-746 \\ Asahimachi-dori, Chuo-ku, Niigata 951-8518, Japan. \\ Received January 20, 2010; accepted March 11, 2010; published online March 19, 2010
}

\begin{abstract}
Diabetes mellitus is a well known and important risk factor for cardiovascular diseases, including heart failure. A new model of Type 2 diabetes, Tsumura Suzuki Obese Diabetes (TSOD) mice, was introduced recently into the research field of diabetes. The cardiac functions of TSOD mice were studied in comparison with Tsumura Suzuki Non Obesity (TSNO, non-diabetic control) mice, for the first time. In vivo cardiovascular functions were measured by echocardiography and cardiac catheterization at 7, 12 and 18 months old. TSOD mice had no deterioration of cardiac function despite the long-term persistence of severe obesity, hyperglycemia, hyperinsulinemia and hyperlipidemia, including high density lipoprotein (HDL)-cholesterol. No histopathological abnormalities were observed in the heart of TSOD mice, while several histological abnormalities were observed in the pancreas and kidney of TSOD mice. To investigate vascular endothelium function at 7 months old, intravenous injection of acetylcholine (ACh; 1, 3, 10 $\mu \mathrm{g} / \mathrm{kg}$ )- and $N^{\mathrm{G}}$-nitro-L-arginine methyl ester (L-NAME; $50 \mathrm{mg} / \mathrm{kg}$ )-induced mean blood pressure (BP) changes were used. ACh decreased whereas L-NAME increased BP, and no significant differences in BP changes were observed between TSOD and TSNO mice. Moreover, ACh-induced relaxation of the thoracic aortae isolated from TSOD and TSNO mice with intact endothelium were not significantly different. These findings suggest that vascular endothelial cells in TSOD mice are not impaired. It was clearly demonstrated that despite obvious diabetes, cardiac functions of TSOD mice were not impaired even at 18 months old.
\end{abstract}

Key words Type 2 diabetes; Tsumura Suzuki Obese Diabetes mouse; cardiovascular function; vascular endothelial function

Epidemiological studies have clearly demonstrated that diabetic patients are at increased risk of cardiovascular morbidity and mortality. ${ }^{1,2)}$ Over recent years, the prevalence of diabetes mellitus, in particular Type 2 diabetes, has increased significantly in developed countries. Diabetes mellitus is a well known and important risk factor for cardiovascular diseases, especially the development of congestive heart failure. ${ }^{3,4)}$

Many animal models of spontaneous obese Type 2 diabetes have contributed to the elucidation of different aspects of human diabetic syndromes. NSY mice and KK-Ay mice are mildly obese, hyperglycemic and hyperinsulinemia. ${ }^{5,6)}$ C57BL/6J-Lep ${ }^{\mathrm{ob}}$ (ob/ob) mice which lack leptin showed mild hyperglycemia, hyperinsulinemia and massive obesity. These animals reverted to normoglycemia at 7 months of age. ${ }^{6-8)}$ C57BL6/KsJ + Lepr $^{\mathrm{db}}(\mathrm{db} / \mathrm{db})$ mice with mutations impairing leptin receptor signaling showed marked hyperglycemia, hyperinsulinemia and obesity as early as 10 days of age. At 4 to 5 months of age, the animal became more severely hyperglycemic with hypoinsulinemia, weight loss and early death. ${ }^{6,89}$ Tsumura Suzuki Obese Diabetes (TSOD) mice, a relatively new polygenetic model of spontaneous obese Type 2 diabetes mellitus, were established as an inbred line in 1992 and some of the clinical diabetic characteristics by Suzuki et al. ${ }^{10)}$ Male TSOD mice constantly showed signs of obesity and urinary glucose with increased food intake, body weight and some fat weight. Glucose and insulin levels in the blood were high for their age. ${ }^{10,11)}$

Miura et al. reported that the insulin-stimulated translocation of glucose transporter (GLUT) 4 from low-density mi- crosomal membranes to the plasma membrane was significantly reduced in both skeletal muscle and adipose tissue of TSOD mice, and that reduced insulin sensitivity was presumably due to this impaired GLUT4 translocation in both skeletal muscles and adipocytes. ${ }^{12)}$ Hirayama et al. identified three major loci meeting the rigorous criteria for linkage using a whole-genome scan of quantitative trait loci affecting body weight, blood glucose and insulin concentration. ${ }^{13)}$ However, no report has investigated the cardiovascular functions of TSOD mice.

In this study, we first evaluated the cardiac function of TSOD mice in comparison with TSNO mice until 18 months. Furthermore, we examined the vascular endothelial function of both animals, and discussed whether symptoms of a cardiovascular problem, such as heart failure, would develop due to the progression of diabetes.

\section{MATERIALS AND METHODS}

Animals Male TSOD mice and Tsumura Suzuki Non Obesity (TSNO, non-diabetic control) mice at 3, 7,12 and 18 months of age used in this study were purchased from the Institute for Animal Reproduction (Ibaraki, Japan). Three mice were housed in a plastic cage in a non-barrier-sustained animal room maintained at $23 \pm 2{ }^{\circ} \mathrm{C}$ with $50 \pm 10 \%$ relative humidity and a $12 / 12 \mathrm{~h} \mathrm{light/dark} \mathrm{cycle.} \mathrm{They} \mathrm{were} \mathrm{maintained}$ on a basal diet MF (Oriental Yeast Co., Ltd., Tokyo) and water ad libitum. All animal experiments were approved and carried out following the Guideline for Animal Experimentation of Musashino University and Niigata University. 
Measurement of Cardiac Contractility and Hemodynamics Echocardiograph and hemodynamic parameters were measured under $1.5 \%$ isoflurane in pure oxygen gas anesthesia with spontaneous respiration. ${ }^{14)}$ Cardiac functions were evaluated while viewing the short axis of the left ventricle by $2 \mathrm{D}$ echocardiography using a linear scan probe (13 MHz, EUB6500; Hitachi Medical, Tokyo, Japan). B- and M-mode echo-cardiograms were obtained. Both the left ventricular systolic dimension (LVsD) and the left ventricular diastolic dimension (LVdD) were determined to calculate the ejection fraction (EF) and fractional shortening (FS). Left ventricular pressure (LVP), left ventricular end-diastolic pressure (LVEDP), and the 1 st derivatives of LVP $\left(\mathrm{dP} / \mathrm{dt}_{\max }\right.$ and $\mathrm{dP} / \mathrm{dt}_{\min }$ ) were measured using a catheter transducer (SPR-671; Millar Instruments, Houston, TX, U.S.A.), which was inserted into the left ventricle from the right carotid artery. The lead II electrocardiogram (ECG) was monitored, and the heart rate was calculated from R-R intervals of ECG waves. ECG R wave amplitude was calculated. These hemodynamic parameters were recorded after analog to digital conversion on a Power Lab system (AD Instruments, Castle Hill, NSW, Australia) at a $1 \mathrm{kHz}$ sampling rate.

Blood and Tissue Sampling After measuring hemodynamic parameters, whole blood was obtained, and then the heart, pancreas and kidney were removed. Heart weight was measured and the heart weight to body weight ratio (HW/BW) was calculated. These organs were dissected and fixed in $10 \%$ buffered formalin, embedded in paraffin wax by routine processing, and sectioned at $3 \mu \mathrm{m}$ thickness. These sections were stained with hematoxylin-eosin (HE).

Measurement of Biochemical Parameters The collected blood samples were centrifuged to obtain plasma samples, which were examined as described below. Concentrations of the following substances were determined with a Model 680 microplate reader (BIO-RAD Laboratories, CA, U.S.A.) using a kit for each substance: plasma glucose level (Glucose CII-Test; Wako), total cholesterol (T-Cholesterol) level (Cholesterol E-Test; Wako), triglyceride level (Triglyceride E-Test; Wako), high-density lipoprotein (HDL)-cholesterol level (HDL-cholesterol E-Test; Wako) (Wako Pure Chemical Industries, Osaka, Japan), low-density lipoprotein (LDL)-cholesterol level (Cholestest LDL; Daiichi Pure Chemicals, Tokyo, Japan), insulin level (ELISA Insulin Kit; Shibayagi, Gunma, Japan), leptin (Mouse/Rat Leptin ELISA kit; B-bridge, CA, U.S.A.), adiponectin (Quantikine or Mouse Adiponectin/Acrp30; R\&D Systems, MN, U.S.A.) and tumor necrosis factor (TNF)- $\alpha$ (TNF- $\alpha$ ELISA kit; COSMO BIO, Tokyo).

Analysis of Vascular Endothelium Function Sevenmonth-old TSOD and TSNO mice were anaesthetized with $1.5 \%$ isoflurane in pure oxygen gas anesthesia with spontaneous respiration. For the determination of mean blood pressure (blood pressure), a heparin-saline-filled polyethylene tube (PE10; Becton Dickinson, NJ, U.S.A.) connected to a pressure transducer (P50; Gould Statham, CA, U.S.A.) was inserted into the femoral artery. Heart rate was measured from $\mathrm{R}-\mathrm{R}$ intervals of lead II ECG waves. Blood pressure, heart rate and ECG were recorded after analog to digital conversion on a Power Lab system at a $1 \mathrm{kHz}$ sampling rate. Another catheter was placed in the femoral vein for infusion of drugs. Acetylcholine chloride (ACh; Daiichi Sankyo, Tokyo,
Japan) and $N^{\mathrm{G}}$-nitro-L-arginine methyl ester (L-NAME; Sigma-Aldrich, Tokyo, Japan) were dissolved in physiological saline and given intravenously by continuous infusion for $30 \mathrm{~s}$ at a rate of $0.02 \mathrm{ml} / 10 \mathrm{~g} / \mathrm{min}$ using an infusion pump (Model 1140-001; Harvard Apparatus, South Natick, MA, U.S.A.).

Seven-month-old TSOD and TSNO mice were anesthetized with ether. After sacrifice, the thoracic aortae were quickly isolated, carefully cleaned free of excess tissues, and cut into rings about $2 \mathrm{~mm}$ wide. The aortic rings were mounted on two stainless-steel hooks inserted through the lumen of the ring. The bottom hook in each preparation was fixed to an organ bath, whereas the top hook was attached to a force transducer (UL-10GR; Minebea, Tokyo, Japan) mounted on a movable platform, which allowed adjustment of resting tension. Tension changes were recorded via a force-displacement transducer connected to a Power Lab system. Each ring was suspended in a $5 \mathrm{ml}$ organ bath for recording isometric contractions. The bathing solution was Krebs-Hesnseleite solution containing (mM): $\mathrm{NaCl}, 118.4$; $\mathrm{KCl}, 4.7 ; \mathrm{MgSO}_{4}, 1.2 ; \mathrm{KH}_{2} \mathrm{PO}_{4}, 1.2 ; \mathrm{NaHCO}_{3}, 25.0 ; \mathrm{CaCl}_{2}$, 2.5; and glucose, 11.1. The solution was continuously bubbled with $95 \% \mathrm{O}_{2}$ and $5 \% \mathrm{CO}_{2}$ at $36 \pm 0.5^{\circ} \mathrm{C}(\mathrm{pH}$ 7.4). The rings were allowed to equilibrate for $90 \mathrm{~min}$ with an optimal resting tension of $1.0 \mathrm{~g}$. Thereafter, the existence of endothelium was confirmed to have relaxed over $80 \%$ in response to ACh $\left(10^{-6} \mathrm{~mol} / \mathrm{l}\right)$ precontracted with phenylephrine $\left(10^{-7}\right.$ $\mathrm{mol} / \mathrm{l}$; Kowa Pharmaceuticals, Tokyo, Japan). The concentration-response curves of ACh $\left(10^{-9}\right.$ to $\left.10^{-5} \mathrm{~mol} / \mathrm{l}\right)$ were made by cumulative application precontracted with phenylephrine $\left(10^{-7} \mathrm{~mol} / \mathrm{l}\right)$. The $\mathrm{p} D_{2}$ values of $\mathrm{ACh}$ were calculated.

Drugs All other reagents of analytical grade were from Wako Pure Chemical Industries (Osaka, Japan).

Statistical Analysis All values are expressed as the mean \pm S.E.M. and analyzed by Student's $t$-test for two groups. $p$ values of less than 0.05 were considered significant.

\section{RESULTS}

Body Weight and Biochemical Parameters Figure 1 shows the body weight, HW/BW, plasma glucose levels, insulin levels, T-cholesterol levels, and triglyceride levels of TSOD and TSNO mice. The body weight of TSOD mice exceeded $60 \mathrm{~g}$ from 3 months old and was significantly greater than that of TSNO mice $(p<0.01)$ at each matched age of 3 , 7, 12 and 18 months. The heart of TSOD mice was heavier than that of TSNO mice aged 7,12 and 18 months (data not shown); however, HW/BW was decreased in the TSOD groups as a result of a significantly elevated body weight between 3 and 18 months of age.

The plasma glucose level exceeded $300 \mathrm{mg} / \mathrm{dl}$ at the age of 3 months and was significantly higher than that of TSNO mice at age of 3,7 and 12 months $(p<0.01)$. The maximum insulin and triglyceride levels of TSOD mice were $32.9 \pm 0.2 \mathrm{ng} / \mathrm{ml}$ and $282 \pm 29 \mathrm{mg} / \mathrm{dl}$, respectively, at 12 months of age, and were significantly higher than those of TSNO mice at $3,7,12$ and 18 months of age $(p<0.01)$. The T-cholesterol levels of TSOD mice were significantly higher than those of TSNO mice at 3,7 and 12 months of age $(p<0.01)$. 
Table 1. Summary of Plasma LDL- and HDL-Cholesterol Levels of TSOD and TSNO Mice at 3, 7, 12 and 18 Months of Age

\begin{tabular}{|c|c|c|c|c|c|c|c|c|}
\hline & \multicolumn{2}{|c|}{3 months } & \multicolumn{2}{|c|}{7 months } & \multicolumn{2}{|c|}{12 months } & \multicolumn{2}{|c|}{18 months } \\
\hline & $\begin{array}{c}\text { TSNO } \\
(n=10)\end{array}$ & $\begin{array}{c}\text { TSOD } \\
(n=10)\end{array}$ & $\begin{array}{l}\text { TSNO } \\
(n=7)\end{array}$ & $\begin{array}{l}\text { TSOD } \\
(n=8)\end{array}$ & $\begin{array}{c}\text { TSNO } \\
(n=10)\end{array}$ & $\begin{array}{c}\text { TSOD } \\
(n=10)\end{array}$ & $\begin{array}{l}\text { TSNO } \\
(n=4)\end{array}$ & $\begin{array}{l}\text { TSOD } \\
(n=5)\end{array}$ \\
\hline LDL cholesterol ( & $17.0 \pm 1.4$ & $15.8 \pm 1.1$ & $9.8 \pm 0.9$ & $17.3 \pm 1.1^{* *}$ & $10.0 \pm 0.5$ & $19.5 \pm 1.7 * *$ & $42.3 \pm 14.1$ & $29.9 \pm 5.1$ \\
\hline HDL cholesterol (mg/dl) & $136.2 \pm 8.5$ & $226.5 \pm 8.9^{* *}$ & $106.3 \pm 3.1$ & $128.0 \pm 5.0^{* *}$ & $104.8 \pm 2.0$ & $119.2 \pm 5.4^{*}$ & $98.3 \pm 5.9$ & $139.6 \pm 9.3 * *$ \\
\hline
\end{tabular}

Data represent the mean \pm S.E.M. of 4 to 10 animals. $* p<0.05 ; * * p<0.01 v$ s. age-matched TSNO mice.
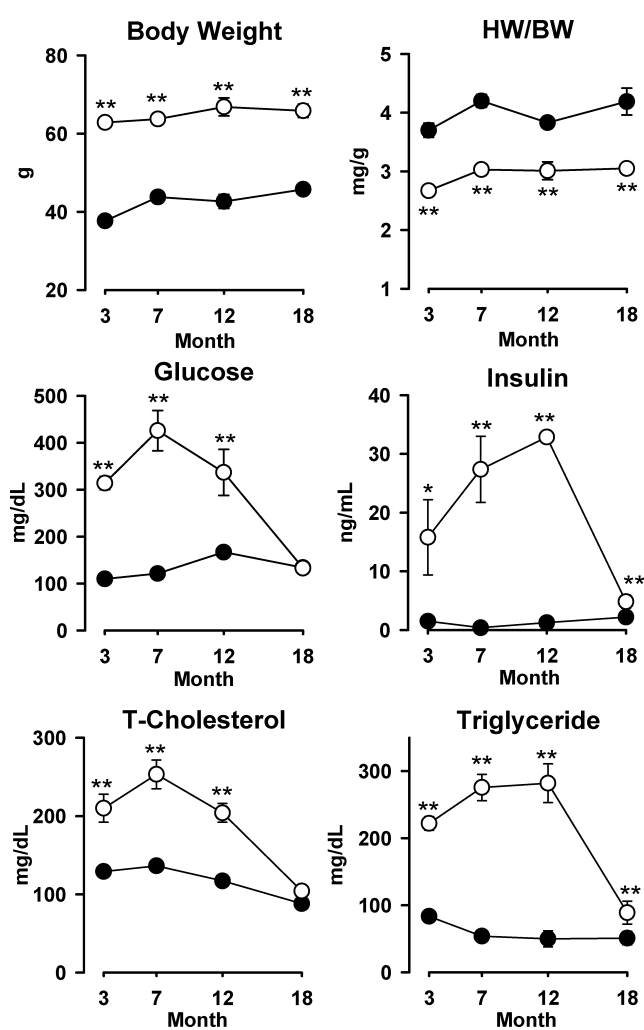

Fig. 1. General and Biochemical Characterization of TSOD and TSNO Mice

HW/BW: heart weight/body weight, open circle: TSOD mice, closed circle: TSNO mice. Data represent the mean \pm S.E.M. of 4 to 15 animals. $* p<0.05$ and $* * p<0.01 v s$. age-matched TSNO mice.

LDL-cholesterol levels of TSOD mice were significantly higher than those of TSNO mice at 7 and 12 months of age (Table 1). HDL-cholesterol levels of TSOD mice were significantly higher than those of TSNO mice at 3, 7, 12 and 18 months of age (Table 1). Adiponectin level of TSOD mice was significantly lower than those of TSNO mice, while leptin and TNF- $\alpha$ levels of TSOD mice were significantly higher than those of TSNO mice at 3 months of age (Table 2).

Cardiac Functions The ventricular cavity of TSOD mice aged 12 months was reduced compared with TSOD mice by B- and M-mode echocardiography (Fig. 2A). The LVdD of TSOD mice was significantly decreased compared with TSNO mice aged 7 months $(4.33 \pm 0.06 \mathrm{~mm} \mathrm{vs.} 4.70 \pm$ $0.09 \mathrm{~mm}, p<0.01), 12$ months $(4.17 \pm 0.09 \mathrm{~mm}$ vs. $4.58 \pm$ $0.13 \mathrm{~mm}, p<0.05)$ and 18 months $(4.00 \pm 0.06 \mathrm{~mm} v s .4 .55 \pm$ $0.12 \mathrm{~mm}, p<0.01)$. The LVsD of TSOD mice was also significantly decreased compared with TSNO mice aged 7 months $(2.78 \pm 0.05 \mathrm{~mm}$ vs. $3.30 \pm 0.06 \mathrm{~mm}, p<0.01), 12$ months $(2.64 \pm 0.06 \mathrm{~mm}$ vs. $3.36 \pm 0.17 \mathrm{~mm}, p<0.01)$ and 18
Table 2. Summary of Plasma Leptin, Adiponectin and TNF- $\alpha$ Levels of TSOD and TSNO Mice at 3 Months of Age

\begin{tabular}{lrr}
\hline \hline & TSNO & \multicolumn{1}{c}{ TSOD } \\
\hline Leptin $(\mathrm{ng} / \mathrm{ml})$ & $4.5 \pm 1.1$ & $30.2 \pm 4.4^{* *}$ \\
Adiponectin $(\mathrm{ng} / \mathrm{ml})$ & $5.2 \pm 0.2$ & $2.7 \pm 0.2^{* *}$ \\
TNF- $\alpha(\mathrm{pg} / \mathrm{ml})$ & $4.7 \pm 0.1$ & $11.1 \pm 1.1 * *$ \\
\hline
\end{tabular}

Data represent the mean \pm S.E.M. of 7 to 9 animals. $* * p<0.01$ vs. age-matched TSNO mice.
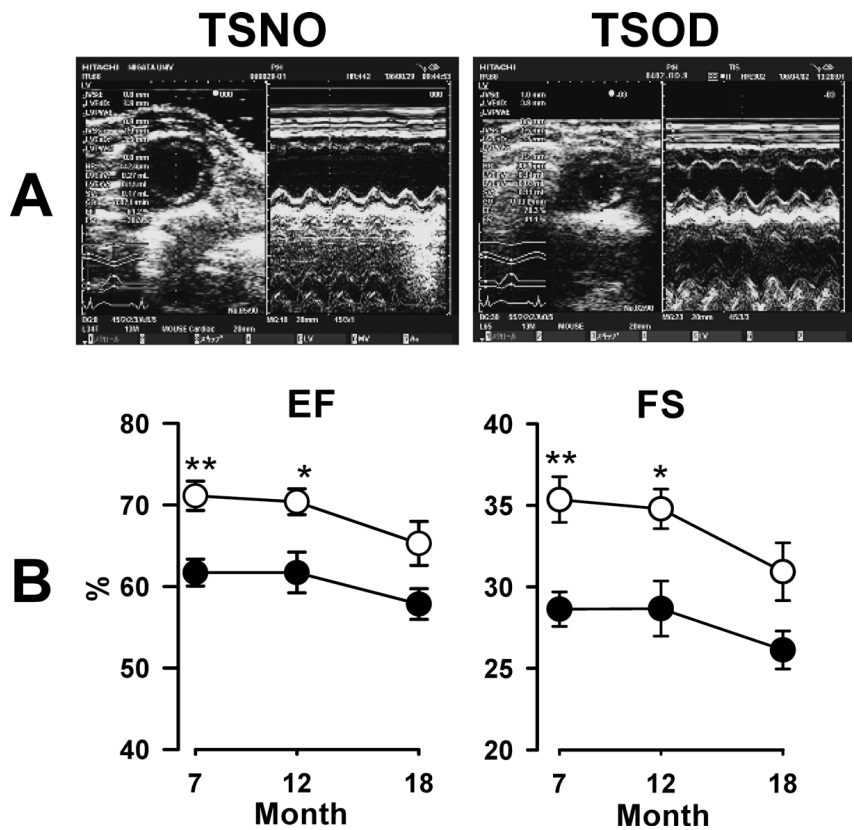

Fig. 2. Echocardiographic Data of TSOD and TSNO Mice

(A) Short-axis view of the left ventricular cavity with echocardiography and M-mode recording. (B) FS: left ventricular fractional shortening, EF: left ventricular ejection fraction, open circle: TSOD mice, closed circle: TSNO mice. Data represent the mean \pm S.E.M. of 4 to 7 animals. $* p<0.05$ and $* * p<0.01 v s$. age-matched TSNO mice.

months $(2.76 \pm 0.12 \mathrm{~mm}$ vs. $3.38 \pm 0.12 \mathrm{~mm}, p<0.01)$. The EF of TSOD mice was significantly higher than that of TSNO mice aged 7 months $(71.1 \pm 1.8 \%$ vs. $61.7 \pm 1.7 \%)$ and 12 months $(70.4 \pm 1.6 \%$ vs. $61.7 \pm 2.5 \%$, Fig. $2 \mathrm{~B}, \mathrm{EF})$. The FS of TSOD mice was also significantly higher than that of TSNO mice aged 7 months $(35.4 \pm 1.4 \%$ vs. $28.6 \pm 1.1 \%)$ and 12 months $(34.8 \pm 1.2 \%$ vs. $28.7 \pm 1.7 \%$, Fig. $2 \mathrm{~B}, \mathrm{FS})$.

The hemodynamics of TSOD and TSNO mice are shown in Fig. 3. The $\mathrm{dP} / \mathrm{dt}_{\max }$ of TSOD mice was significantly higher than that of TSNO mice aged 7 months (8118士 $322 \mathrm{mmHg} / \mathrm{s}$ vs. $5745 \pm 309 \mathrm{mmHg} / \mathrm{s}, p<0.01), 12$ months $(8003 \pm 555 \mathrm{mmHg} / \mathrm{s}$ vs. $5262 \pm 86 \mathrm{mmHg} / \mathrm{s}, p<0.01)$ and 18 months $(7934 \pm 638 \mathrm{mmHg} / \mathrm{s}$ vs. $5369 \pm 125 \mathrm{mmHg} / \mathrm{s}, \quad p<$ 0.01). The $\mathrm{dP} / \mathrm{dt}_{\min }$ of TSOD mice was significantly lower 

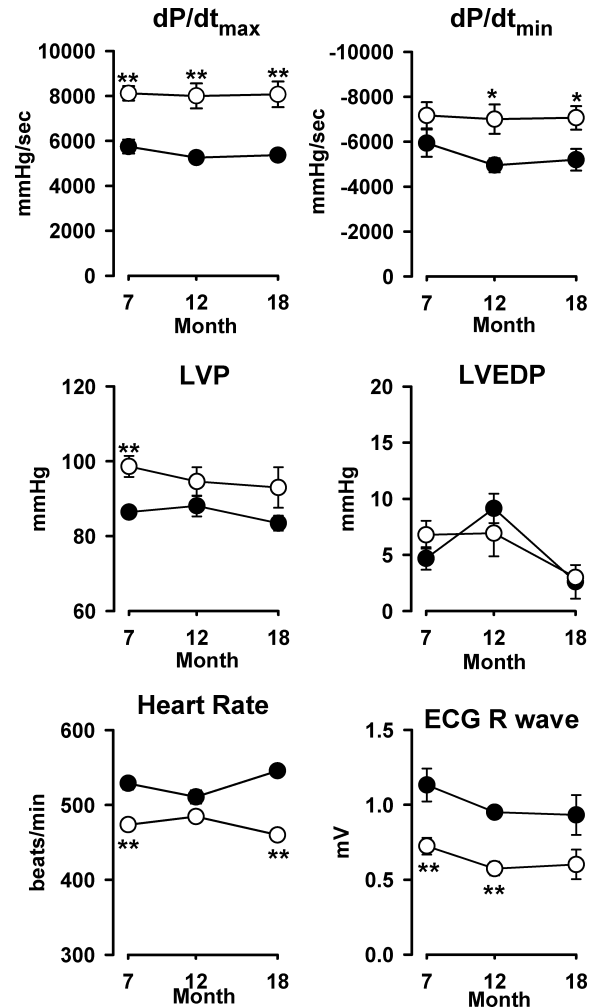

Fig. 3. Hemodynamic Indices of TSOD and TSNO Mice

$\mathrm{dP} / \mathrm{dt}_{\text {max }}$ : maximum derivative of left ventricular pressure, $\mathrm{dP} / \mathrm{dt}_{\text {min }}$ : minimum derivative of left ventricular pressure, LVP: left ventricular pressure, LVEDP: left ventricular end-diastolic pressure, ECG R wave: ECG R wave amplitude, open circle: TSOD mice, closed circle: TSNO mice. Data represent the mean \pm S.E.M. of 4 to 7 animals. $* p<0.05$ and $* * p<0.01 v s$. age-matched TSNO mice.

than that of TSNO mice aged 12 months $(-7004 \pm 658$ $\mathrm{mmHg} / \mathrm{s} v s .-4956 \pm 314 \mathrm{mmHg} / \mathrm{s}, p<0.05)$ and 18 months $(-6757 \pm 492 \mathrm{mmHg} / \mathrm{s}$ vs. $-5195 \pm 537 \mathrm{mmHg} / \mathrm{s}, p<0.05)$. The LVP of TSOD mice had a higher tendency than TSNO mice. The LVEDP was not significantly different between TSOD and TSNO mice. The heart rate of TSOD mice tended to be lower than that of TSNO mice. The R wave amplitude of TSOD mice was significantly lower than that of TSNO mice aged 7 months $(0.72 \pm 0.06 \mathrm{mV}$ vs. $1.13 \pm 0.11 \mathrm{mV})$ and 12 months $(0.58 \pm 0.05 \mathrm{mV}$ vs. $0.95 \pm 0.04 \mathrm{mV})$.

Light Microscopy of Pancreas, Kidney and Heart Light microscopy observations of the pancreas revealed hypertrophy of pancreatic islets in TSOD mice aged 12 months, but it was not observed in TSNO mice (Fig. 4A). In the kidney of TSOD mice, several histological abnormalities, an increased mesangial area in the glomerulus (Fig. 4B), dilation of the pelvic cavity and urinary tubules, thickening of the basement membrane in glomeruli, were observed markedly at 18 months of age, while at 12 months of age no remarkable alterations were observed. These alterations were not observed in the kidney of TSNO mice. The light microscopy findings of the hearts at 18 months old are shown in Fig. 4C. No abnormalities, such as necrosis, fibrosis and cardiac hypertrophy, were observed in either TSNO or TSOD mice.

Analysis of Vascular Endothelium Function The initial blood pressure of TSNO and TSOD mice was 72.9 \pm $1.5 \mathrm{mmHg}(n=4)$ and $78.4 \pm 2.4 \mathrm{mmHg}(n=4)$, respectively. One, 3 and $10 \mathrm{mg} / \mathrm{kg}$ ACh decreased the blood pressure dose-

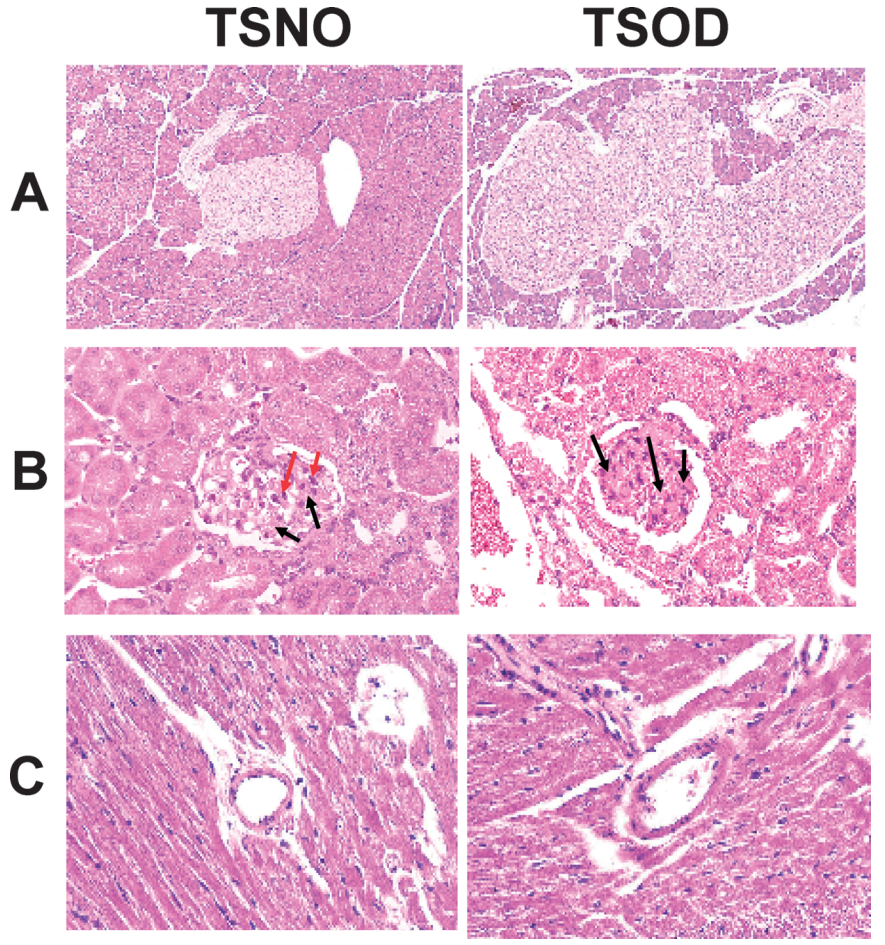

Fig. 4. Light Microscopic Features of the Pancreas, Kidney and Heart in TSNO and TSOD Mice

HE stained samples. (A) Severe hypertrophy observed in TSOD mice at 12 months of age $(\times 25)$. (B) Increased mesangial area (black arrow) in the glomerulus was observed in TSOD mice at 18 months of age. Normal mesangial area (black arrow) and mesangial cells (red arrow) in glomerulus were observed in TSNO mice $(\times 100)$. (C) The hearts did not show any abnormalities, such as necrosis, fibrosis and cardiac hypertrophy, in both TSNO and TSOD mice at 18 months of age $(\times 80)$.
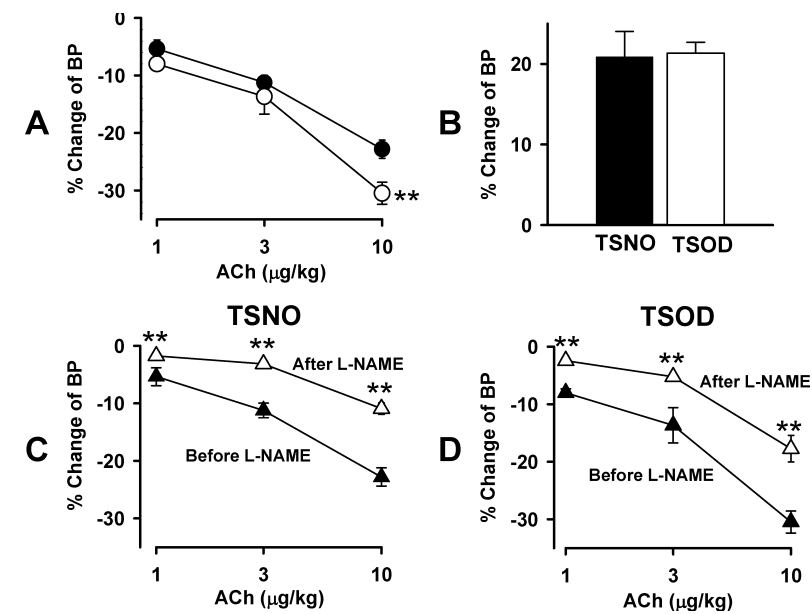

Fig. 5. Effects of ACh and L-NAME on Mean Blood Pressure in TSOD and TSNO Mice

BP: mean blood pressure. (A) Effects of ACh on BP. open circle: TSOD mice, closed circle: TSNO mice. (B) Effects of L-NAME ( $N^{\mathrm{G}}$-nitro-L-arginine methyl ester) on BP ( 5 min after injection). Inhibitory effects of L-NAME on the hypotensive effects of ACh in TSNO mice (C) and TSOD mice (D). Data represent the mean \pm S.E.M. of 4 animals. $* * p<0.01 v s$. TSNO mice (A), or $v s$. value before L-NAME (C, D).

dependently after intravenous administration to both TSNO and TSOD mice. Figure 5A shows the percent changes from the blood pressure just before administration. The decreases of blood pressure with ACh (up to $3 \mu \mathrm{g} / \mathrm{kg}$ ) in both TSOD and TSNO mice had no significant effect, while the hypotensive effect with $10 \mu \mathrm{g} / \mathrm{kg}$ ACh in TSOD mice was signifi- 
cantly greater than in TSNO mice. L-NAME at a dose of $50 \mathrm{mg} / \mathrm{kg}$ given intravenously produced a rise of blood pressure to a similar extent in both TSNO and TSOD mice (Fig. 5B). The hypotensive effects with $\mathrm{ACh}(1,3,10 \mathrm{mg} / \mathrm{kg})$ after L-NAME were inhibited compared with those before LNAME in TSNO mice (Fig. 5C). Similar inhibition with LNAME was observed in TSOD mice (Fig. 5D).

In the isolated thoracic aorta with an intact endothelium precontracted by phenylephrine $\left(10^{-7} \mathrm{~mol} / \mathrm{l}\right)$, ACh $\left(10^{-8}\right.$ $\left.10^{-5} \mathrm{~mol} / \mathrm{l}\right)$ produced marked relaxation in both TSNO and TSOD mice. Maximum contractile response by phenylephrine $\left(10^{-7} \mathrm{~mol} / \mathrm{l}\right)$ in TSOD mice was not different from that in TSNO mice. The $\mathrm{p} \mathrm{D}_{2}$ values of $\mathrm{ACh}$ in TSNO and TSOD mice were $6.64 \pm 0.19(n=6)$ and $6.27 \pm 0.13(n=6)$, respectively, and were not significant.

\section{DISCUSSION}

We studied the cardiac functions, biochemical parameters and tissue histology of Type 2 diabetes mellitus model mice, TSOD mice, and non-diabetic mice, TSNO mice at 3, 7, 12 and 18 months of age. TSOD mice showed hyperglycemia and hyperlipidemia between 3 and 12 months of age (Fig. 1). The levels of insulin, triglyceride, HDL-cholesterol and body weight of TSOD mice were significantly higher than those of TSNO mice between 3 and 18 months of age (Fig. 1, Table 1). Moreover, the levels of leptin and TNF- $\alpha$ in TSOD mice were significantly higher and the level of adiponectin in TSOD mice was significantly lower than those in TSNO mice at 3 months of age (Table 2). The levels of leptin, TNF$\alpha$ and adiponectin have been well recognized as adipocytederived bioactive substances, adipocytokines. Plasma leptin was found to be highly correlated with body mass index (BMI) in rodents and in humans. ${ }^{15)}$ TNF- $\alpha$ also correlated obesity and insulin resistance. ${ }^{16,17)}$ However, adiponectin which is recognized as antidiabetic protein, correlated inversely with obesity and insulin resistance. ${ }^{18)}$ In the pancreas and kidney of TSOD mice, severe histological abnormalities were observed at the age of 12 and 18 months (Figs. 4A, B). Although many Type 2 diabetes animal models have been developed, only TSOD mice are a model with high levels of glucose, insulin, triglyceride and lipids maintained as long as 12 or 18 months. Furthermore, TSOD mice have several features similar to the pathologic condition and diabetic complications of human diabetes Type 2, including visceral fat accumulation, glucose tolerance, insulin tolerance, hypertension and peripheral neuropathy. ${ }^{11,12,19)}$ However, since TSOD mice had no deterioration of cardiac function except low $\mathrm{R}$ wave amplitude and myocardial damage in pathologic findings, despite their advanced age of 18 months, it seems that there was no onset of heart failure with diabetes (Figs. 2, 3, 4C). Contrary to expectations, cardiac functions of TSOD mice, such as EF, FS and $\mathrm{dP} / \mathrm{dt}$, were significantly higher than those of TSNO mice (Figs. 2, 3). Although deterioration of the myocardium may cause low $\mathrm{R}$ wave amplitude, mechanical function and abnormal pathological signs were not observed; thus, this phenomenon may not be the reason. The heart size of TSOD mice was smaller than that of TSNO, and low electrical conductive fat tissue of TSOD mice was larger than that of TSNO. It is suggested that these factors may contribute to the low $\mathrm{R}$ wave amplitude.
The vascular endothelium function of TSOD mice was evaluated in comparison with TSNO mice in both an in vivo and in vitro study. The hypotensive effect of ACh (up to $3 \mu \mathrm{g} / \mathrm{kg}$ ) in both TSOD and TSNO mice was not significant, while the hypotensive effect of $10 \mu \mathrm{g} / \mathrm{kg}$ ACh in TSOD mice was significantly greater than in TSNO mice (Fig. 5A). The hypertensive effect of L-NAME, considered to be the result from which nitric oxide was eliminated, was similar in both TSNO and TSOD mice (Fig. 5B). Moreover, inhibition of ACh-induced hypotensive effects with L-NAME was similar in both TSNO and TSOD mice (Figs. 5C, D). ACh induced equivalent relaxation responses of isolated thoracic aorta with intact endothelium in both TSNO and TSOD mice. These results suggest that the vascular endothelial cells of TSOD mice are not impaired, and thus, it is considered that the endothelium function of TSOD mice might be maintained, as in the case of TSNO mice.

In rodent models of obesity and Type 2 diabetes, several functional and structural alterations of the heart and cardiac muscle have been documented; however, most studies have been performed in an isolated perfused heart. In vivo studies of $\mathrm{ob} / \mathrm{ob}$ and $\mathrm{db} / \mathrm{db}$ have provided evidence for systolic and diastolic dysfunction by echocardiographic study, ${ }^{20-22)}$ whereas some in situ studies using cardiac catheterization in Type 2 diabetes animals argue that the cardiac function is maintained. ${ }^{23-26)}$ Cardiac catheterization revealed significantly increased LV contractility and relaxation $\left(\mathrm{dP} / \mathrm{dt}_{\max }\right.$ and $\mathrm{dP} / \mathrm{dt}_{\text {min }}$ ) in ob/ob mice at 4 and 15 weeks of age. ${ }^{24)}$ Another study revealed that $\mathrm{EF}, \mathrm{dP} / \mathrm{dt}_{\max }$ and cardiac output were maintained in $\mathrm{db} / \mathrm{db}$ at 12 and 24 weeks of age. ${ }^{25)}$

In general, it is recognized that these rodent models are resistant to arteriosclerosis disease in coronary artery and spontaneous ischemia, which exist in many humans with diabetes mellitus. HDL-cholesterol levels are inversely related to atherosclerosis susceptibility in humans and mice. ${ }^{27-29)}$ The protective properties of HDL-cholesterol may be due to its role in reverse cholesterol transport and to antioxidant and anti-inflammatory effects in the arterial wall. ${ }^{30)}$ The increasing HDL-cholesterol plasma levels normalize impaired endothelial functions in hypercholesterolemic patients. ${ }^{31,32}$ ) These data may provide insight into the protective role of HDL-cholesterol on atherogenesis in hyperlipidemia. ${ }^{32}$ The $\mathrm{ob} / \mathrm{ob}$ mice are resistant to atherosclerosis and a high level of HDL-cholesterol. ${ }^{33-35)}$ HDL-cholesterol level in TSOD mice was significantly higher than that of TSNO mice, although the levels of T-cholesterol and LDL-cholesterol in TSOD mice were significantly higher than in TSNO mice (Fig. 1, Table 1). In human diabetes, according to the impairment of coronary circulation and endothelium function, myocardial ischemia and heart failure develop; however, with TSOD mice, in order that arteriosclerosis might not occur, it was thought that cardiovascular disease did not arise. The high HDL-cholesterol level in TSOD mice is mentioned as one of the causes of the maintenance of cardiac function.

High glucose concentration itself induced a significantly higher rate of apoptosis as measured with the TUNEL assay in adult rat ventricular myocytes in vitro, ${ }^{36-38)}$ and the number of dead myocytes increased. ${ }^{36-38)}$ Despite the long period of hyperglycemia, the deterioration of cardiac function in TSOD mice was not detected. On the other hand, the cardiac function parameters such as EF, FS and $\mathrm{dP} / \mathrm{dt}$ of TSOD mice 
were significantly higher than that of TSNO mice (Figs. 2, 3 ). Since the heart rate of TSOD mice was significantly lower compared with TSNO mice (Fig. 3), this improved cardiac function of TSOD mice may not be due to the activation of sympathetic nerve. Although we need further study to determine the mechanism(s), we speculate that the high blood glucose level which increases energy metabolism may be one reason. Moreover, in TSOD mice, cardiomyocytes may be protected by a particular mechanism(s) against high glucose toxicity. Solving this mechanism(s) which protects cardiomyocytes will require further study.

The biochemical parameters of TSOD mice reverted to normal values at around 18 months of age. Reduction of the insulin level in blood may be followed by the decline of insulin secretion due to the deficiency of B cells. As a cause of decreased glucose and the T-cholesterol levels, reduction in enzymes response activity by decreased food consumption will be considered, an alteration that might be associated with aging.

TSOD mice are a useful model of spontaneous obese Type 2 diabetes mellitus and metabolic syndrome, because they maintain the pathophysiological process of diabetes for a long period of time. They are also expected to be a model of renal dysfunction, since several types of glomerular damage to the kidney and polyuria were observed in TSOD mice. Iizuka et al. reported that pancreas islets in TSOD mice were hypertrophied over 6 months of age, due to proliferation and swelling of B cells. ${ }^{11)}$ These histopathologic alterations were similar to the findings seen in diabetes mellitus patients. It is suggested that TSOD mice may be a useful model for studying diabetes-induced dysfunction of the kidney and pancreas.

This study is the first one that examined the cardiovascular function of TSOD mice. In conclusion, TSOD mice showed severe obesity, hyperglycemia, hyperinsulinemia, hypertriglyceridemia, hyperlipidemia and abnormality of the pancreas and kidney between 3 and 12 or 18 months of age; however, no cardiovascular and endothelial dysfunction or histopathologic abnormalities of the heart were observed. Therefore, this mouse model may not be suitable as a diabetes-induced heart failure model, but may be a good model for studying diabetes-induced dysfunction of the kidney and pancreas.

Acknowledgements This work was supported in part by the "High-Tech Research Center" Project for Private Universities: matching fund subsidy from MEXT (Ministry of Education, Culture, Sports, Science and Technology of Japan) (2004-2008).

\section{REFERENCES}

1) Garcia M. J., McNamara P. M., Gordon T., Kannel W. B., Diabetes, 23, 105-111 (1974).

2) Kannel W. B., McGee D. L., JAMA, 241, 2035-2038 (1979).

3) Kannel W. B., Hjortland M., Castelli W. P., Am. J. Cardiol., 34, 29-34 (1974).

4) Nichols G. A., Hillier T. A., Erbey J. R., Brown J. B., Diabetes Care, 24, 1614-1619 (2001).

5) Ueda H., Ikegami H., Yamato E., Fu J., Fukuda M., Shen G., Kawaguchi Y., Takekawa K., Fujioka Y., Fujisawa T., Nakagawa Y., Hamada Y., Shibata M., Ogihara T., Diabetologia, 38, 503-508 (1995).

6) Mordes J. P., Rossini A. A., Am. J. Med., 70, 353-360 (1981).

7) Genuth S. M., Przybylski R. J., Rosenberg D. M., Endocrinology, 88,
$1230-1238(1971)$

8) Coleman D. L., Hummel K. P., Diabetologia, 3, 238-248 (1967).

9) Coleman D. L., Diabetes, 31 (Suppl. 1, Pt. 2), 1-6 (1982).

10) Suzuki W., Iizuka S., Tabuchi M., Funo S., Yanagisawa T., Kimura M., Sato T., Endo T., Kawamura H., Exp. Anim., 48, 181-189 (1999).

11) Iizuka S., Suzuki W., Tabuchi M., Nagata M., Imamura S., Kobayashi Y., Kanitani M., Yanagisawa T., Kase Y., Takeda S., Aburada M., Takahashi K. W., Exp. Anim., 54, 71-83 (2005).

12) Miura T., Suzuki W., Ishihara E., Arai I., Ishida H., Seino Y., Tanigawa K., Eur. J. Endocrinol., 145, 785-790 (2001).

13) Hirayama I., Yi Z., Izumi S., Arai I., Suzuki W., Nagamachi Y., Kuwano H., Takeuchi T., Izumi T., Diabetes, 48, 1183-1191 (1999).

14) Kawada T., Nakazawa M., Nakauchi S., Yamazaki K., Shimamoto R., Urabe M., Nakata J., Hemmi C., Masui F., Nakajima T., Suzuki J., Monahan J., Sato H., Masaki T., Ozawa K., Toyo-Oka T., Proc. Natl. Acad. Sci. U.S.A., 99, 901-906 (2002).

15) Maffei M., Halaas J., Ravussin E., Pratley R. E., Lee G. H., Zhang Y., Fei H., Kim S., Lallone R., Ranganathan S., Nat. Med., 1, 1155-1161 (1995).

16) Hotamisligil G. S., Nature (London), 444, 860-867 (2006).

17) Uysal K. T., Wiesbrock S. M., Marino M. W., Hotamisligil G. S., Nature (London), 389, 610-614 (1997).

18) Hotta K., Funahashi T., Arita Y., Takahashi M., Matsuda M., Okamoto Y., Iwahashi H., Kuriyama H., Ouchi N., Maeda K., Nishida M., Kihara S., Sakai N., Nakajima T., Hasegawa K., Muraguchi M., Ohmoto Y., Nakamura T., Yamashita S., Hanafusa T., Matsuzawa Y., Arterioscler. Thromb. Vasc. Biol., 20, 1595-1599 (2000).

19) Shimada T., Kudo T., Akase T., Aburada M., Biol. Pharm. Bull., 31, 1362-1367 (2008).

20) Semeniuk L. M., Kryski A. J., Severson D. L., Am. J. Physiol. Heart Circ. Physiol., 283, H976-H982 (2002).

21) Pereira L., Matthes J., Schuster I., Valdivia H. H., Herzig S., Richard S., Gomez A. M., Diabetes, 55, 608-615 (2006).

22) Christoffersen C., Bollano E., Lindegaard M. L., Bartels E. D., Goetze J. P., Andersen C. B., Nielsen L. B., Endocrinology, 144, 3483-3490 (2003).

23) Abe T., Ohga Y., Tabayashi N., Kobayashi S., Sakata S., Misawa H., Tsuji T., Kohzuki H., Suga H., Taniguchi S., Takaki M., Am. J. Physiol. Heart Circ. Physiol., 282, H138-H148 (2002).

24) Buchanan J., Mazumder P. K., Hu P., Chakrabarti G., Roberts M. W., Yun U. J., Cooksey R. C., Litwin S. E., Abel E. D., Endocrinology, 146, 5341-5349 (2005).

25) Van den Bergh A., Flameng W., Herijgers P., Eur. J. Heart Fail., 8, 777-783 (2006).

26) Barouch L. A., Berkowitz D. E., Harrison R. W., O’Donnell C. P., Hare J. M., Circulation, 108, 754-759 (2003).

27) The Lipid Research Clinics Coronary Primary Prevention Trial Results. I. JAMA, 251, 351-364 (1984).

28) The Lipid Research Clinics Coronary Primary Prevention Trial Results. II. JAMA, 251, 365-374 (1984).

29) Breslow J. L., Curr. Opin. Lipidol., 5, 175-184 (1994).

30) Berliner J. A., Navab M., Fogelman A. M., Frank J. S., Demer L. L., Edwards P. A., Watson A. D., Lusis A. J., Circulation, 91, 2488-2496 (1995).

31) Spieker L. E., Sudano I., Hurlimann D., Lerch P. G., Lang M. G., Binggeli C., Corti R., Ruschitzka F., Luscher T. F., Noll G., Circulation, 105, 1399-1402 (2002).

32) Lupattelli G., Marchesi S., Roscini A. R., Siepi D., Gemelli F., Pirro M., Sinzinger H., Schillaci G., Mannarino E., Am. J. Cardiol., 90, 648 - 650 (2002).

33) Paigen B., Morrow A., Brandon C., Mitchell D., Holmes P., Atherosclerosis, 57, 65-73 (1985).

34) Silver D. L., Jiang X. C., Tall A. R., J. Biol. Chem., 274, 4140-4146 (1999).

35) Yen T. T., Allan J. A., Pearson D. V., Schinitsky M. R., Experientia, 33, 995-996 (1977).

36) Fiordaliso F., Bianchi R., Staszewsky L., Cuccovillo I., Doni M., Laragione T., Salio M., Savino C., Melucci S., Santangelo F., Scanziani E., Masson S., Ghezzi P., Latini R., J. Mol. Cell Cardiol., 37, 959-968 (2004).

37) Malhotra A., Kang B. P., Hashmi S., Meggs L. G., Mol. Cell Biochem., 268, 169-173 (2005).

38) Shizukuda Y., Buttrick P. M., Am. J. Physiol. Heart Circ. Physiol., 282, H320-H327 (2002). 